\title{
Comparison of Life Satisfaction and Attitude towards Disability between Congenital
}

\section{and Acquired Physical Disabilities}

\author{
* Roza Jamal, Lecturer \\ ** Mrs. Wajeeha Komal, Lecturer \\ *** Mr. Sarfraz Ahmad, PhD Scholar (Correspondence Author)
}

\begin{abstract}
The most common physical deformity includes upper and lowers limbs deformity that could be acquired or congenital. Such deformity produces difficulty in daily life activities including reaching, walking, lifting, and carrying things. The present study aimed to explore life satisfaction and attitude towards disability between congenital and acquired physical disabilities. A sample of eighty $(N=80)$ participants was included in the study out of which $(n=40)$ were congenital and $(n=40)$ were acquired physical disables. The sample was collected from different rehabilitation and paraplegic centers as well as institutions through the purposive sampling technique. Satisfaction with life scale and attitude toward disabled person scales were included. It was hypothesized that there will be a significant difference in terms of life satisfaction between congenital and acquired physical disables. The second hypothesis was the attitude towards disability will be positive among the congenital group than the acquired one. An independent sample t-test (IBM SPSS statistics version 20) was applied to analyze the difference between congenital and acquired physical disables. Results of the study indicated that congenital physical disabled were found with highly satisfied from their life $(\alpha=.000)$ and possess a positive attitude towards disability $(\alpha=.000)$ than the acquired physical disables.
\end{abstract}

Keywords: Satisfaction, Disability, Congenital, Deformity, Limbs.

\section{Introduction}

Life satisfaction is one's perception of happiness and feelings about one life (Lippman, Guzman, \& Moor, 2012). It can be defined as "pleasure and happiness an individual ga ined from his or her life and one's belief that his/her life is on the right track" (Ardahan \& Mert, 2013). Different researchers worked on life satisfaction and its relation with a physical disability as Nosek, Fuhrer, and Potter (1995) studied individuals with physical disabilities and it was found that they were less satisfied with their life. It was concluded that degree of handicap decreases the level of life satisfaction and it is one of the basic reasons for limitation in social role performance. It was also found that life satisfaction is more related to personal assistance. The more individual is satisfied with his assistance in terms of cost, quality, and control, the more he will be satisfied with his life. Life satisfaction and satisfaction from personal assistance are positively correlated.

According to Cho (2015), functional disability and life satisfaction are negatively associated. If one increases the other decreases. The decrease in one aspect increases the other. Self-rated health and life satisfaction are positively correlated. Another research revealed that individuals with physical disabilities involved in sport were found more satisfied with life in comparison to those who never participate in such activities. People involved in sports were found with good mental health as compared to those who are not involved in sports (Mockeviciene \& Savenkoviene, 2012). Recent research revealed that the life satisfaction of many active individuals is different from those who are less active and less involved in exercises and sports-. The results showed that active individuals were satisfied with their life as compared to those who were not active (Nemcek, 2016).

Researchers worked on physical disability to study either the congenital disabled accept their disability early or the acquired ones. It was assumed that congenital disabled accept and are better adapted to disability than the acquired one and predicted that congenital life satisfaction would be high as compared to the acquired one. Participants completed an online questionnaire measuring life

\footnotetext{
* Department of Education \& Psychology, KUST, Kohat Email: roza.jamal@kust.edu.pk

** Department of Education \& Psychology, KUST, Kohat Email: psychology4every1@gmail.com

*** Email: sarfraz206@gmail.com
} 
satisfaction and self-efficacy. Results showed that self-efficacy, self-esteem, the identity of a disabled, and income were the predictors of life satisfaction and congenital disables were highly satisfied as compared to the acquired disabled (Bogart, 2014).

According to Ostlie, Permagnus, Skjeldal, Garfield, and Jambs (2011), an individual's life satisfaction and mental health are affected due to upper limb amputation. Hopkins symptom checklist 25 -items and Satisfaction with life scale were used. Through multiple linear regression analysis results were identified. Results showed that the life satisfaction and mental health scores were found lower among people with lower limb amputation and also declared that long-term complications related to amputees lead to low satisfaction of life. The research was conducted to study lower limb amputee and their satisfaction with life for their functional capacity in terms of physical functioning, dependency, mental health, and social relations. Forty (40) elderly persons were selected which included thirty (30) men and ten (10) women. The mean age was 74.5 years. Different scales were applied that is the Barthel index and Cantrill model. Among 40 elderly persons, general life satisfaction was high. It was found that there was no existence of a relationship between life satisfaction and functional capacity. Life satisfaction and the domain of health and physical functioning were found positively correlated (D'Elboux Diogo, 2003)

A study proclaims that the physical disabled's attitude towards disability is positive if they are provided with certain kinds of care and support. Disables who live in rehabilitation centers are found more satisfied and with a positive attitude towards disability as compared to those who decline rehabilitation centers. Physical disabled in rehabilitation centers reported a positive attitude because they were provided with good facilities in rehabilitation centers (Lilja, Bergh, Johansson, \& Nygard, 2003). Attitude towards disability differs across different countries. The social distance scale was used by Chinese medical practitioners, Greek, Arabic, Italian, German, and Anglo Australian communities used to assess the attitude of people towards the disabled. Among them, German expressed a positive attitude towards the disabled as compared to other communities (Westbrook, Legge, \& Pennay, 1993).

One of the most important topics in the research area is an individual with a disability. The research was conducted by Huskin, Robbins, and Kwon (2017) to study student's attitudes towards physical disability and to check how the relationship experiences with the disabled create changes in one's attitude. Hence results showed that a positive attitude develops due to an increase in contact with the disabled.

Another research was conducted to investigate the relationship of contact with the disabled and increase in the rate of positive attitude among different kinds of disabilities. Results specified that people with cognitive impairment (developmental disabilities) were treated with negative attitudes and a person in a wheelchair (general physical disabilities) was treated with a positive attitude. The result showed that contact with the disabled decreases the negative attitude and helps to better understand disability-related bias (Barr \& Bracchitta, 2014). The research was conducted to find the attitude of disabled and caregivers towards disability and it was found that disabled attitude was positive as compared to the caregiver (Zheng et al., 2016). Attitude towards disability depends on the acceptance of disability. The positive attitude towards disability reveals that individual has accepted their disability and has a positive attitude towards other disabilities as well (Snead \& Davis, 2002). Through a Cross-sectional study, attitudes towards the disability of physical disabled were studied among 1,853 people with physical disabilities in China. Results concluded that the physically disabled had an unfavorable attitude towards disability (Zheng et al., 2014).

\section{Lite rature Review}

Concerning life satisfaction, a closely related phenomenon is the attitude towards disability. It is defined as "an individual believes and feelings that influence an individual to perform in a certain way (Brostrand, 2006). In general, attitude is defined as an assessment about someone or something either positive or negative and expressed through one's behavior (Simrandeep, 2011). Disability viewed by people as disgrace, shameful, tragedy, and object of pity, produces guilt among the disabled, their family members, and those who are associated with them and they start counting themselves as a burden to themselves and others as well. It happens just because of discrimination and segregation. A woman with a disability is counted as worse. According to Tervo and Palmer (2004), the attitude of health professional students towards disability was less positive and need specific educational experiences to promote a positive attitude. They hold a negative attitude, especially nursing undergraduate students. 
Public attitude towards disability is one of the major problems in rehabilitation centers. A disabled person is well prepared to perform a job and to live a normal life but due to employer attitude towards disability, they can't find employment, and the disabled are counted as an underprivileged minority group. As there is the existence of racial and religious prejudice, in the same way, there is the existence of prejudice towards disability (Tringo, 1970).

Another research was conducted about the attitude of healthcare professionals towards physical disability after one year of participation in learning programs for caring for the physically disabled. The attitude towards disabled person scale was applied and results declared that participation and completion of educational programs lead to a positive attitude towards physical disability. The positive attitude towards the physically disabled has a positive influence on the disabled patient's response towards betterment, treatment, and self-acceptance maintenance (Oermann \& Lindgren, 1995).

According to Ingstad (2001), one of the major challenges faced by the physically disabled is the reaction and attitude of peers towards their disability. Every person has stereotypical ideation and misunderstanding about physical disables such as calling a person with a disability name. It also includes harassment such as moving away from a disabled person, which is often the result of fear or lack of knowledge. It affects an individual with a physical disability, their attitude towards disability becomes negative. They feel insecure and having a sense of failure which leads to loneliness, lack of inspiration to learn, and an increase in absence from school. Physical disabled face problems during employment. They remain at a disadvantage because no such promotions and decision powers are given to them. They are not at an equal right to others. If a physical disabled find itself in a difficult situation at a workplace such as unfair treatment, the disabled person will find it hard to speak up for their right because of fear of being dismissed from the job. Their attitude towards their rights is suppressed.

The current study based on the above literature review and focused on the Comparison of life Satisfaction and Attitude towards Disability between Congenital and Acquired Physical D isabilities in the Peshawar culture.

\section{The rationale of the study:}

The literature review focused on Upper and lower limb physical disability which includes daily life difficulties as reaching, lifting, carrying things, and walking, etc., (Jabeen et al., 2016). Physical disability includes congenital and acquired conditions and both cause inadequacies in various perspectives (Change \& Johnson, 2008). Most people become physically disabled (Acquired) because of trauma that as accidents (railway and road accidents), falling or machine injuries, etc. (Dhole et al., 2015). Center for disease control and prevention revealed that by birth (Congenital) upper limb reduction is as common as lower limb reduction and the affected face different problems that as motor skills deficits, need someone's help, and feel embarrassed because of physical appearance (Yang et al., 1997). Every year 750 babies are born with lower limb reduction and 1500 babies are with upper limb reduction (Canfield et al., 2006). Life satisfaction in congenital physical disables is higher as compared to acquired physical disables (Hawang, Johnston \& Smith, 2009) and Attitude towards disability has been found with acceptance of disability. If a disabled attitude towards disability is positive then automatically, he or she will accept his or her disability and have a positive attitude towards others disability as well (Snead \& Davis, 2002). Keeping in mind the above-mentioned researches (Jabeen et al., 2016; Change \& Johnson, 2008; Dhole et al., 2015; Yang et al., 1997; Canfield et al., 2006; Hawang, Johnston \& Smith, 2009 and Snead \& Davis, 2002). The present research brings a holistic work about the Comparison of Life satisfaction and Attitudes toward disability between Congenital and acquired physical disables based on upper and lower limb disability in Peshawar, Pakistan. This research brings a piece of work, which studied the basic difference between congenital and acquired physical disables. One of the basic aims of the research is to focus on specific phys ical disabilities that are upper and lower limb physical disabilities and then compared this two-group based on two domains that are life satisfaction and attitude towards disability. Being disabled is one of the most challenging problems to live in an environment, where the majority population lived with the ir normal body function. Through this research, it was studied that how the acquired physical disabled affected when suddenly he/she lose his /her body's normal functions through accidents/trauma. Physical disability is not only about physical losing but it also affects a disabled psychologically. This study 
brings how their self-esteem, body esteem, life satisfaction, and attitude towards disability are affected when they face daily life challenges. It studies how a person is affected when suddenly body function loss occurs as compared to those who are by birth disabled. Comparison gives us a conclusion that acquired physical disabled are more affected because he/she grew up with normal body function. Sudden loss of body function hit them psychologically and they are not satisfied with their lives and have a negative attitude towards disability as compared to those with congenital physical disables. This research impels us towards an idea that every paraplegic center and hospital should have a psychologist, who should help a disabled person to accept their disability and help the person to count their disability in itself as ability.

\section{Research Question}

How can we find out the life satisfaction and attitude towards disability among congenital and acquired physical disables?

Objectives

- To understand life satisfaction among congenital and acquired physical disables.

- To explore the attitude towards disability among congenital and acquired physically disabled.

\section{Hypotheses}

1. There will be a significant difference in terms of life satisfaction between congenital and acquired physical disables.

2. Attitude towards disability will be positive among the congenital group than the acquired one.

\section{Statement of the problem}

The study aims to make the comparison of Life Satisfaction and Attitude towards Disability between Congenital and Acquired Physical Disabilities.

\section{Methodology}

\section{Sample}

The sample consisted of $80(\mathrm{~N}=80)$ participants of congenital $(n=40)$ and acquired $(n=40)$ physical disabilities determined through a purposive sampling technique to meet the objective of the study, belonging to the age range of $15-45$ years.

\section{Demographic Sheet}

For the current study, a detailed demographic sheet was used. This demographic sheet caters to the basic information i.e. gender, age, the onset of physical disability, birth order, education level, family system (joint/nuclear), number of family members, marital status, occupation, and type of disability (upper or lower limb).

\section{Instruments}

Satisfaction with life scale was developed by Diener et al (1985). It consists of five items and it is made to measure the life satisfaction of an individual. Usually, it takes lesser time to answer these items on a seven-point Likert scale. As 7-Strongly agree, 6-Agree, 5-Slightly agree, 4-Neither agree nor disagree, 3-Slightly disagree, 2-Disagree, and 1-Strongly disagree. The process involves adding up all the scores. The obtained scores ranging from 31-35 indicates extremely satisfied, 26-30 satisfied, 21-25 slightly satisfied, 20-24 indicates slightly dissatisfied, 15-19 slightly dissatisfied, 1014 dissatisfied, and 5-9 extremely dissatisfied. Diener et al., 1985 reported 0.82 coefficient alpha and 2-month test-retest stability coefficient 0.82 and shown strong internal reliability and moderate temporal reliability. Urdu version of this scale was used in the study. Its Urdu translation is done by Butt, Ghani, and Khan from the Department of Psychology, GC University, Lahore, Pakistan in 2014.

Attitude towards disabled persons scale form $\mathrm{O}$ was developed by Yuker, Block, and Young in 1970. This scale is used for measuring an individual's attitude toward disability. It consists of 20 Questions a six-point Likert scale. On this scale, +3 represents agree very much to -3 which represents disagree very much. Reverse scored items are five i.e. 2, 5, 6, 11, and 12 . Internal validity will be found by reversing the sign of the sum and the numerical value of 60 is added to the sum of the scores for a composite score. If composite scores are high then it will show more positive attitudes towards the person with a disability. Its reliability coefficient ranges from +.72 to .85 .

\section{Mode of Data Collection}

In the current research, before data collection, different rehabilitation centers were approached, which included Paraplegic Centre Peshawar, Rafsan Rehabilitation Centre, Rehabilitation Centre for the physically disabled Peshawar (RCPD), and Shaheed Benazir Bhutto Women University Peshawar to obtain informed consent for data collection. The sample included individuals with disabilities specific 
to upper and lower limb deformity. Ethical consideration was kept in mind throughout the procedure. The participants were informed about the purpose of the research. The researcher informed participants that the collected data will be used for research purposes only and the results will be kept confidential. After taking the informed consent, the booklet comprising of the mentioned four tests along with a demographic sheet was provided to each participant individually to have responses from them. After the collection of data, the results were compiled through an Independent Sample t-test by using the Statistical Package of Social Sciences (SPSS).

\section{Inclusion Crite ria}

- $\quad$ Only upper and lower limb disables were included.

\section{Exclusion criteria}

- $\quad$ Participants above age 45 were not included.

- Individuals other than upper and lower limb disabilities were excluded.

\section{Results and Discussion}

Table 1

Socio-demographic information $(\mathrm{N}=80)$

\begin{tabular}{|c|c|c|c|}
\hline & $\mathrm{f}$ & Percent & Cumulative Percent \\
\hline \multicolumn{4}{|l|}{ Subjects } \\
\hline Acquired & 40 & 50.0 & 50.0 \\
\hline Congenital & 40 & 50.0 & 50.0 \\
\hline \multicolumn{4}{|l|}{ Gender } \\
\hline Male & 49 & 61.3 & 61.3 \\
\hline Female & 31 & 38.8 & 100.0 \\
\hline \multicolumn{4}{|l|}{ Age } \\
\hline $15-30$ & 47 & 58.8 & 58.8 \\
\hline $30-45$ & 33 & 41.3 & 100.0 \\
\hline \multicolumn{4}{|c|}{ Marital status } \\
\hline Married & 29 & 36.3 & 36.3 \\
\hline Unmarried & 51 & 63.7 & 100.0 \\
\hline \multicolumn{4}{|l|}{ Birth order } \\
\hline $1-3$ & 46 & 57.5 & 57.5 \\
\hline 3-6 & 28 & 35.0 & 92.5 \\
\hline $6-10$ & 6 & 7.5 & 100.0 \\
\hline \multicolumn{4}{|c|}{ Education level } \\
\hline Uneducated & 19 & 23.8 & 23.8 \\
\hline Matric & 35 & 43.8 & 67.5 \\
\hline F.Sc & 16 & 20.0 & 87.5 \\
\hline BA & 6 & 7.5 & 95.0 \\
\hline Masters & 4 & 5.0 & 100.0 \\
\hline \multicolumn{4}{|c|}{ Family system } \\
\hline Joint & 44 & 55.0 & 55.0 \\
\hline Nuclear & 36 & 45.0 & 100.0 \\
\hline \multicolumn{4}{|c|}{ No. of family members } \\
\hline $1-5$ & 51 & 63.0 & 63.7 \\
\hline $5-10$ & 29 & 37.0 & 100.0 \\
\hline \multicolumn{4}{|c|}{ Onset of disability } \\
\hline $1-5$ & 44 & 55.0 & 55.0 \\
\hline $15-30$ & 33 & 41.3 & 96.3 \\
\hline $30-45$ & 03 & 3.8 & 100.0 \\
\hline \multicolumn{4}{|c|}{ Type of disability } \\
\hline Upper limb & 15 & 18.8 & 18.8 \\
\hline Lower limb & 65 & 81.3 & 100.0 \\
\hline
\end{tabular}

Table no. 1 provides us a detailed description of congenital $(\mathrm{f}=40)$ and acquired $(\mathrm{f}=40)$ physical disables. The majority of participants were male $(\mathrm{f}=49)$ while the female $(\mathrm{f}=31)$ were found less in number. The majority were unmarried $(\mathrm{f}=51)$ and educated $(\mathrm{f}=61)$ and belongs to a joint family ( $\mathrm{f}-44$ ). Most of them were found with lower limb physical disability ( $f=65)$. 
Table 2

Mean, Standard Deviation, Skewness, Kurtosis, and Alpha Coefficient of SWLS and ATDP Scales

\begin{tabular}{lccccccc}
\hline Scales & $\begin{array}{c}\text { no. of } \\
\text { Items }\end{array}$ & $N$ & Mean & $S D$ & skewness & kurtosis & $\begin{array}{c}\text { Alpha } \\
\text { Coefficient }\end{array}$ \\
\hline SWLS & 05 & 80 & 18.52 & 8.82 & .098 & -1.326 & .898 \\
ATDP & 20 & 80 & 82.73 & 15.86 & -.790 & .226 & .751 \\
\hline
\end{tabular}

Note: SWLS=satisfaction with life scale, ATDP=attitude towards disabled person scale.

Table 2 presents the value of the arithmetic mean, standard deviation, skewness, kurtosis, and alpha coefficient of reliability estimate. The value of skewness and kurtosis indicates that the data is normally distributed while alpha coefficient values indicate high reliability.

Table 3

Inter item correlation for satisfaction with life scale.

\begin{tabular}{cccccc} 
& 1 & 2 & 3 & 4 & 5 \\
\hline 1 & 1.000 & - & - & - & - \\
2 & .631 & 1.000 & - & - & - \\
3 & .604 & .677 & 1.000 & - & - \\
4 & .628 & .545 & .574 & 1.000 & - \\
5 & .700 & .690 & .614 & .737 & 1.000 \\
\hline
\end{tabular}

According to the above table all items are significantly correlated with each other which show that all items are measuring the same construct, proving the construct validity of the scale.

\section{Table 4}

Inter item correlation for attitude toward disabled person scale.

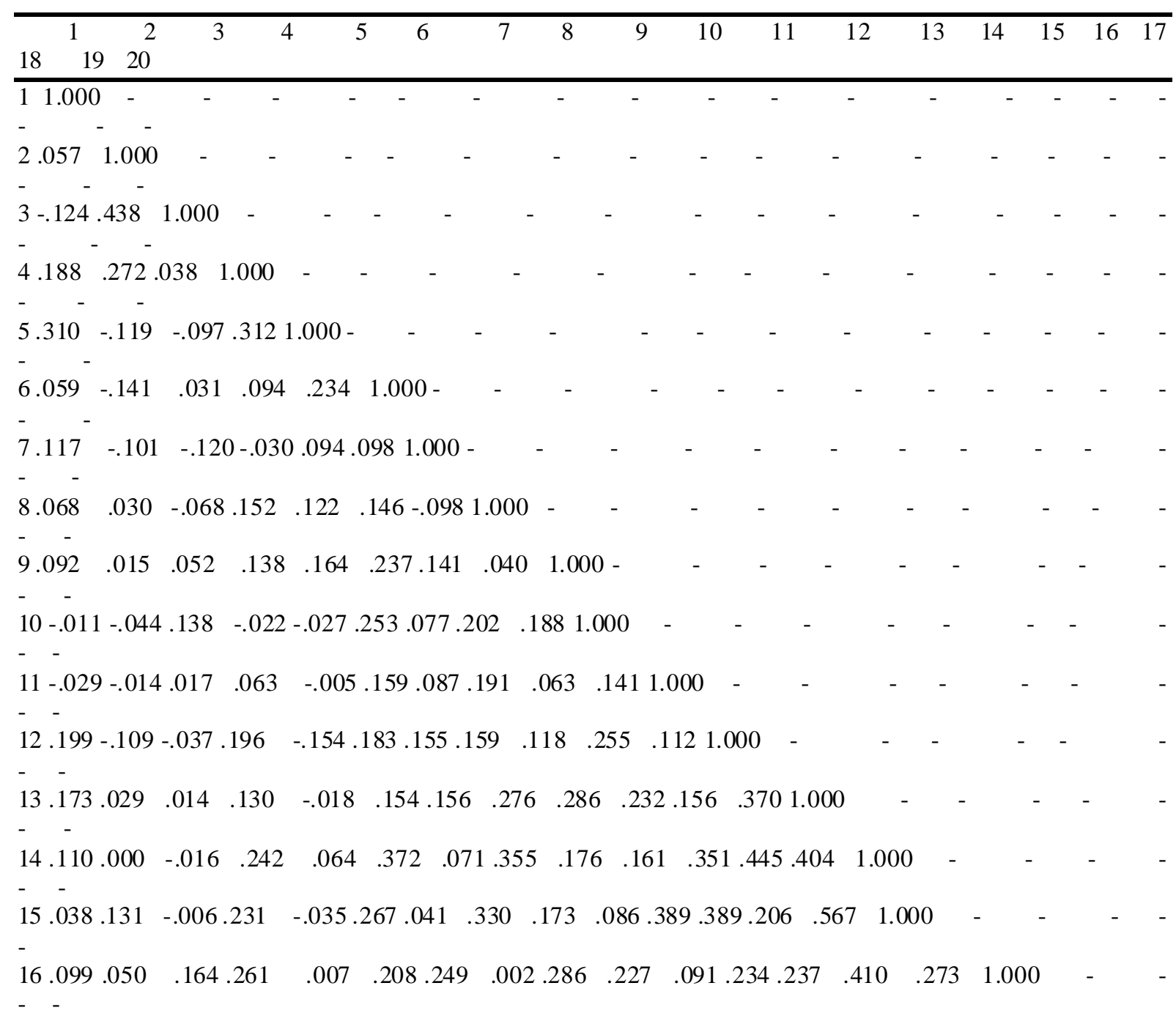




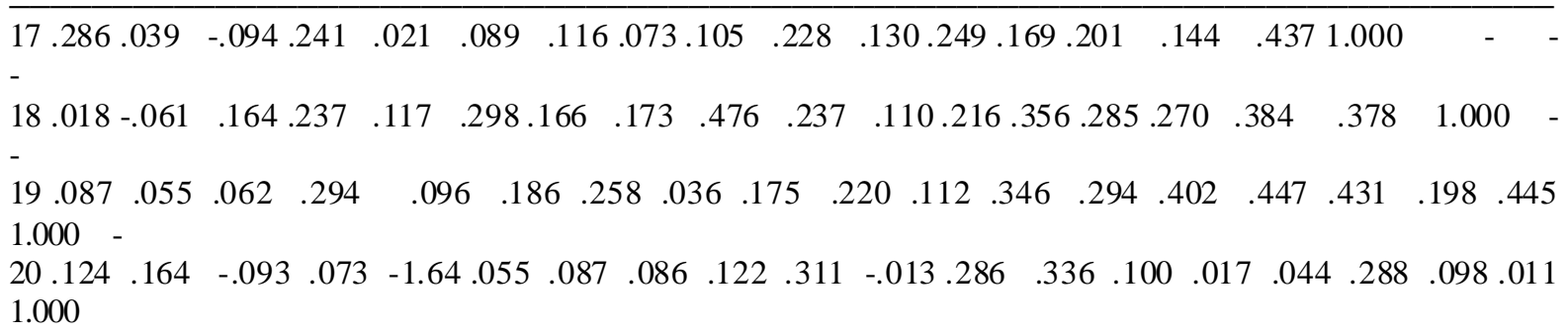

According to the above table all items are significantly correlated with each other which show that all items are measuring the same construct, proving the construct validity of the scale.

Table 5

Mean, standard deviation, and t value of satisfaction with life scale between congenital and acquired physical disability

\begin{tabular}{|c|c|c|c|c|c|c|c|c|c|}
\hline \multirow[b]{3}{*}{ Scale } & \multicolumn{4}{|c|}{ Physical disables } & \multirow[b]{3}{*}{$T$} & \multirow[b]{3}{*}{$P$} & & & \multirow{3}{*}{$\begin{array}{l}\text { Cohen's } \\
D\end{array}$} \\
\hline & \multirow{2}{*}{$\begin{array}{l}\text { Acquired } \\
(n=40) \\
M\end{array}$} & & \multicolumn{2}{|c|}{$\begin{array}{l}\text { Cong en ital } \\
(n=40)\end{array}$} & & & \multicolumn{2}{|l|}{$95 \% \mathrm{CI}$} & \\
\hline & & $S D$ & $M$ & $S D$ & & & $L L$ & $U L$ & \\
\hline SWLS & 10.80 & 4.08 & 26.25 & 4.31 & -16.439 & 0.000 & -17.32 & -13.57 & 3.67 \\
\hline
\end{tabular}

Note: SWLS= Satisfaction with life scale, ${ }^{*} \mathrm{p}<0.05$

Table 5 shows the difference between congenital and acquired physical disables on satisfaction with life scale. Congenital physical disables tended to have high life satisfaction as compared to acquired physical disables. The value of Cohen's $d(d=3.67)$ indicates a high effect size

Table 6

Mean, standard deviation, and $t$ value of attitude toward disabled person scale between congenital and acquired physical disability

\begin{tabular}{|c|c|c|c|c|c|c|c|c|c|}
\hline \multirow[b]{4}{*}{ Scale } & \multicolumn{4}{|c|}{ Physical disables } & \multirow[b]{4}{*}{$T$} & \multirow[b]{4}{*}{$P$} & & & \multirow{4}{*}{$\begin{array}{l}\text { Cohen's } \\
D\end{array}$} \\
\hline & \multirow{2}{*}{\multicolumn{2}{|c|}{$\begin{array}{l}\text { Acquired } \\
(n=40)\end{array}$}} & \multicolumn{2}{|c|}{ Congenital } & & & & & \\
\hline & & & $(n=40)$ & & & & $95 \% \mathrm{CI}$ & & \\
\hline & $M$ & $S D$ & $M$ & $S D$ & & & $L L$ & $U L$ & \\
\hline ATDP & 51.05 & 12.66 & 91.92 & 10.26 & -15.861 & 0.000 & -14.19 & -.359 & 3.54 \\
\hline
\end{tabular}

Note: $\mathrm{ATDP}=$ Attitude toward disabled person scale, ${ }^{*} \mathrm{p}<0.05$

Table 6 shows the difference between congenital and acquired physical disables on attitude toward disabled person scale. Congenital physical disables tended to have a positive attitude towards physical disability as compared to acquired physical disables. The value of Cohen's $d(d=3.54)$ indicates a high effect size.

Overall result findings concluded that high life satisfaction and positive attitude towards disability is present among congenital physical disables as compared to acquired physical disables.

\section{Discussion}

Current research assumed that there will be the existence of difference in terms of life satisfaction between congenital and acquired physical disables. Results supported our hypothesis by showing a significant difference $(\mathrm{t}=-16.439, \mathrm{p}=0.000)$ between congenital and acquired physical disables. Table 5 showed that congenital physical disables possess high life satisfaction than the acquired physical disables that is in line with the findings of Kinney and Coyle (1992) that congenital physical disables do possess high life satisfaction as compared to acquired physical disables.

A study conducted by Mollaoglu, Tuncay, and Fertelli (2010) about people with a mobility disability and their life satisfaction. Life satisfaction and mobility disability were found correlated. Life satisfaction is affected by the level of health perception and the factor which affects one's life satisfaction is an individual disability. Another study revealed that satisfaction and acceptance of lower limb amputation were positively associated and these results supported the hypothesis of the current study (Pereira et al., 2018). 
Trauma is one of the fundamental and most important causes of physical disability in adults living in Nigeria. Therefore life satisfaction was studied among physically disabled dwelling in rural communities of Southwest Nigeria. A positive correlation was found between reintegration to normal living and respondents' life satisfaction $(\mathrm{r}=0.539, \mathrm{p}=0.001)$. Physical disabled with trauma were found with low to moderate levels of reintegration into life activities and were not unsatisfied with their life after traumatic injury. Integration of people after trauma was significantly associated with the level of affectation and also related to life satisfaction after physical disability (Olaoye, Adejumobi, Olasusi, Aladesuyi \& Emechete, 2017).

Dillingham, Pezzin, Mackenzie, and Burgees (2001) examined and documented life satisfaction among people with traumatic limb amputation. The data was collected through follow-up and medical interviews. It included 78 amputees and these patients reported dissatisfaction from life because of wounds, skin irritation, and pain. The results declared that people living with traumarelated amputation and use of prosthesis devices were found dissatisfied. High injury severity also contributes to poor life satisfaction among traumatic physically disabled.

It was also hypothesized that attitude towards disability will be positive among the congenital group than the acquired one. The results supported the hypothesis. A significant difference $(t=-15.861$ and $\mathrm{p}=0.000$ ) was found between congenital and acquired physical disables. Table 6 shows that appositive attitude was possessed by congenital physical disables in comparison to the acquired one. Zheng et al., (2014) found that phys ically disabled have an unfavorable attitude towards disability and according to Snead and Davis (2002), a positive attitude towards disability leads to acceptance of disability and enhances a positive attitude towards others disability as well. According to Hosain, Atkinson, and Underwood (2002), physical disability harmed the physical disabled's emotional state, one's education, jeopardized their employment, and also create difficulty in their social life. Society looked at them negatively which results in a negative effect on their psychological and social health. Altman (1981) described society's negative attitude towards disability as a critically adverse effect on the physically disabled. As a result, they lose interest, become isolated and count their disability as a barrier in performing successfully in soc iety and they always blame their fate and they consider it as a divine punishment. Fear of disease and misunderstanding leads to emotional distress. Physical disables avoid other disables due to fear of further stigmatization through association. Disables do not desire to be relating with other groups belongs to impairment (Deal, 2006).

Kuvalekar (2015) studied congenital as well as acquired physical disables. It was found that most acquired respondents need help in activities related to daily living including stair climbing and movements (mobility) activities such as mobility and stair climbing. Life quality scores were found poor under different domains concerning the psychological aspects. Domains include poor appearance, negative attitude, and low self-esteem of the participant. According to Bogart, Rosa, and Slepian (2018) congenital physical disable have less hostile attitudes as compared to an acquired physical disables. Congenital physical disables blamed themselves much as compared to the acquired physical disables. According to Valizadeh, Dadkhah, Mohammadi, and Hassankhani (2013) in an acquired physical disability, patients show a non-adaptive attitude towards their amputation. They are unable to accept these abrupt changes in their life. Patients experience fatigue, long-term changes in life, medical costs, economic burden, and the most affecting factor is the absence of friends and family support.

Another research proclaims that attitude towards disability depends on the acceptance of disability. Those disabled who accept their disability generate a positive attitude towards other disabled as well (Snead \& Davis, 2002).

Our current study provides a unique opportunity to examine congenital and acquired physical disability. It contributes to finding different perspectives related to their life; it includes life satisfaction and attitude towards disability. The above-given literature review supports our hypotheses and helps in study deeply about congenital and acquired physical disabilities.

\section{Conclusions}

This research analyses the difference between congenital and acquired physical disables, focusing on life satisfaction and attitude towards disability. Results declared a significant difference among these two groups that is congenital and acquired physical disables. The congenital physical disabled never experienced normal body movements such as walking etc and holding things normally in their hands. They are by birth disabled that's why they are not affected that much as compared to acquired 
physical disabled. Acquired physical disabled lose their potentiality through accidents and trauma, which leads to functional loss of body parts fully or partially due to which they become physically disabled.

The congenital physical disabled were found to be highly satisfied from the ir life, possess a positive attitude towards physical deformity in comparison to acquired physical disables while the acquired physical disables were found less satisfied from their life and have a negative attitude towards their disability because they are unable to accept their traumatic physical deformity.

\section{Implications:}

The current research contributed to the provided literature review by investigating the difference between congenital and acquired physical disables. This research demonstrated that a physically disabled needs care and support. Parents, friends, siblings, and colleagues should take care of physically disabled persons.

Centers for Physical disabled in Pakistan should hire psychologists to help the physically disabled to assist them emotionally and psychologically so that they may accept their disability. Acceptance towards disability is important to an individual so that to move forward in one's life (especially acquired physical disables) and once they accept their disability it contributes to high satisfaction from life and retains a positive attitude towards disability. The significance of the current study is that it focused on understanding the variables in Pakistani culture and especially in Peshawar, Pakistan.

\section{Limitations and Suggestions}

Despite efforts to build a study limitation free, the current research contains certain limitations and suggestions which are as follows;

1. Current research contained fewer female participants as compared to males. In the subsequent studies, the sample of females could be increased and should approach other cities as well.

2. The current research was conducted on upper and lower limbs' physical disabilities. In future studies, researchers might work on other kinds of physical disability like acquired brain injury, hearing, and visual impairments and respiratory disorders, etc.

3. Many studies have been conducted on public attitude towards disability but very few researches are conducted on disable's attitude towards disability. Researchers might work on disable's attitude towards disability.

4. Lifts should be constructed in schools and colleges for disabling's support and care.

5. In the disabled quota, job opportunities should be increased to help them to earn for their families.

6. Paraplegic and rehabilitation centers should be increased by the government and other organizations (non-government).

\section{References}

Altman, B. M. (1981). Studies of attitudes toward the handicapped: The need for a new direction. Social problems, 28(3), 321-337

Ardahan, F., \& Mert, M. (2013). Impacts of outdoor activities, demographic variables and emotional intelligence on life satisfaction: An econometric application of a case in Turkey. Social Indicators Research, 113(3), 887-901.

Barr, J. J., \& Bracchitta, K. (2015). Attitudes toward individuals with disabilities: The effects of contact with different disability types. Current Psychology, 34(2), 223-238.

Bogart, K. R. (2014). The role of disability self-concept in adaptation to congenital or acquired disability. Rehabilitation Psychology, 59(1), 107.

Bogart, K. R., Rosa, N. M., \& Slepian, M. L. (2019). Born that way or became that way: Stigma toward congenital versus acquired disability. Group Processes \& Intergroup Relations, 22(4), 594-612.

Brostrand, H. L. (2006). Evaluating the Tilting at Windmills curriculum's effectiveness in changing attitudes toward people with disabilities in the workplace. Southern Illinois University at Carbondale.

Canfield, M.A., Honien, M.A., Yuskiv, N., Xing, J., Mai, C.T., Collins, J.S., . . Kirby, R.S. (2006). National estimates and race/ethnic-specific variation of selected birth defects in the United States, 1999-2001. Birth Defects Research (Part A): Clinical and Molecular Teratology, 76 (11), 747-756.doi:10.1002/bdra.20294. 


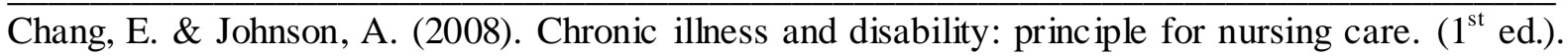
Australia: Elsevier.

Cho, S. (2015). The effects of physical and psychological health on life satisfaction among older adults with a physical disability in South Korea: focus on gender differences. Asia Pacific Journal of Social Work and Development, 25(3), 133-144.

The deal, M. (2006). Attitudes of disabled people toward other disabled people and impairment groups (Doctoral dissertation, City University, London).

D'Elboux Diogo, M. J. (2003). Satisfaction with life overall and with specific life domains among elderly persons with a lower limb amputation. Pan American journal of public health, 13(6), 395-399. Doi: https://doi.org/10.1590/s1020-49892003000500008

Dhole, S. R., Gaur, A. k., More, S. N., Popalwar, H \& Lokhanda, V. (2015). Study of locomotor disability due to various types of trauma, National Journal of Medical Research, 5(3), 194198. Retrieved from http://njmr.in/home/abstrct/515/July-Sep

Dillingham, T. R., Pezzin, L. E., MacKenzie, E. J., \& Burgess, A. R. (2001). Use and satisfaction with prosthetic devices among persons with trauma-related amputations: a long-term outcome study. American journal of physical medicine \& rehabilitation, 80(8), 563-571.

Hawang, K., Johnston, M. V. \& Smith, J. K. (2009). Adult attachment styles and life Satisfaction In an individual with physical disabilities. Journal of Applied Research Quality Life, 4(3), 295310.doi: 10.100/s11482-009-9082-x.

Hosain, G. M., Atkinson, D., \& Underwood, P. (2002). Impact of disability on quality of life of rural disabled people in Bangladesh. Journal of Health, Population, and Nutrition, 297-305.

Huskin, P. R., Reiser-Robbins, C., \& Kwon, S. (2017). Impacts of Vocational Interest on Undergraduate Students' Attitudes toward Persons with Disabilities. Research in Higher Education Journal, 33.

Ingstad, B. (2001). Disability in the developing world. ( $1^{\text {st }}$ ed). London. Sage publication inc.Ltd,

Jabeen, T., Kazmi, S. F., Rehman, A. U \& Ahmed, S. (2016).Upper and lower limbs disability and personality traits. Journal of Ayub Medical College, 28(2), 348-352. Retried from https://jamc.ayubmed.edu.pk/index.php/jamc/article/view/635/295

Kinney, W. B., \& Coyle, C. P. (1992). Predicting life satisfaction among adults with physical disabilities. Archives of physical medicine and rehabilitation, 73(9), 863-869.

Kuvalekar, k., Kamath, R., Ashok, L., Shetty, B., Mayya, S \& Chandrasekaran, V. (2015). Quality of life among persons with physical disability in Udapi Taluk: a cross-sectional study. Journal of Family Medicine and Primary Care, 4 (01), 69-73.

Lilja, M., Bergh, A., Johansson, L., \& Nygard, L. (2003). Attitudes towards rehabilitation needs and support from assistive technology and the social environment among elderly people with disability. Occupational Therapy International, 10(1).

Lippmann, L., Guzman, L. \& Moor, K. A. (2012). Life satisfaction. Retrieved from https://www. ncbi.nlm.nih.gov/pubmed/8456331

Mockeviciene, D. \& Savenkoviene, A. (2012). Aspects of quality of persons with physical disabilities. Journal of Social Welfare Interdisciplinary Approach, 2(2), 84-93.

Mollaoğlu, M., Tuncay, F. O.\& Fertelli, T. K. (2010). Mobility disability and life satisfaction in elderly people. Archives of Gerontology and Geriatrics, 51(3), 115-119. doi:10.1016/j.archger.2010.02.013

Nemček, D. A. G. M. A. R. (2016). Life satisfaction of people with disabilities: a comparison between active and sedentary individuals. Journal of Physical Education and Sport, 16(2), 1084-1088.

Nosek, M. A., Fuhrer, M. J. \& Carel Potter (1995). Life satisfaction of people with physical disabilities: Relationship to personal assistance, disability status, and handicap. Rehabilitation Psychology, 40(03), 191-202.

Oermann, M. H., \& Lindgren, C. L. (1995). An Educational Program's Effects on Students' Attitudes Toward People with Disabilities: A 1-Year Follow-Up. Rehabilitation Nursing, 20(1), 6-10.

Olaoye, O. A., Adejumobi, A. S., Olasusi, A. O., Aladesuyi, O. B., \& Emechete, A. A. (2017). Relationship between community integration and life satisfaction among stroke survivors dwelling in rural communities of the southwest, Nigeria. Journal of Environmental and Occupational Health, 6(1), 19-26. 
Østlie, K., Magnus, P., Skjeldal, O. H., Garfelt, B., \& Tambs, K. (2011). Mental health and satisfaction with life among upper limb amputees: a Norwegian population-based survey comparing adult-acquired major upper limb amputees with a control group. Disability and Rehabilitation, 33(17-18), 1594-1607.

Pereira, M. G., Ramos, C., Lobarinhas, A., Machado, J. C., \& Pedras, S. (2018). Satisfaction with life in individuals with a lower limb amputation: The importance of active coping and acceptance. Scandinavian journal of psychology, 59(4), 414-421.

Simrandeep. (2011). Attitude. Retrieved from https:// www. Slideshare. net/simrandeep/attitude6827762

Snead, S. L., \& Davis, J. R. (2002). Attitudes of individuals with acquired brain injury towards disability. Brain injury, 16(11), 947-953.

Tervo, R. C., \& Palmer, G. (2004). Health professional student attitudes towards people with disability. Clinical Rehabilitation, 18(8), 908-915.

Tringo, J. L. (1970). The Hierarchy Preference towards Disability Groups. The Journal of Special Education, 4(03), 295-306. doi:10.1177/002246697000400306

Valizadeh, S., Dadkhah, B., Mohammadi, E., \& Hassankhani, H. (2014). The perception of trauma patients from social support in adjustment to lower-limb amputation: a qualitative study. Indian Journal of Palliative Care, 20(3), 229.

Westbrook, M. T., Leggev. \& Pennay, M. (1993). Attitude towards disabilities in a multicultural society. Journal of Social Science Med, 36(05), 615-23. Retrieved from http://www. performwell.org.

Yang, Q., Khoury, M.J., Olney, R.S \& Mulinare, J. (1997). Does peri-conceptional Multivitamin use reduce the risk for limb deficiency in offspring? Epidemiology, 8(2), 157-161. Retrieved from https://www.ncbi.nlm.nih.gov/pubmed/9229207

Zheng, Q. L., Tian, Q., Hao, C., Gu, J., Lucas-Carrasco, R., Tao, J. T., ... \& Hao, Y. T. (2014). The role of quality of care and attitude towards disability in the relationship between severity of disability and quality of life: findings from a cross-sectional survey among people with physical disability in China. Health and quality of life outcomes, 12(1), 1-10.

Zheng, Q., Tian, Q., Hao, C., Gu, J., Tao, J., Liang, Z., ... \& Hao, Y. (2016). Comparison of attitudes toward disability and people with disability among caregivers, the public, and people with a disability: findings from a cross-sectional survey. BMC public health, 16(1), 1-10. 